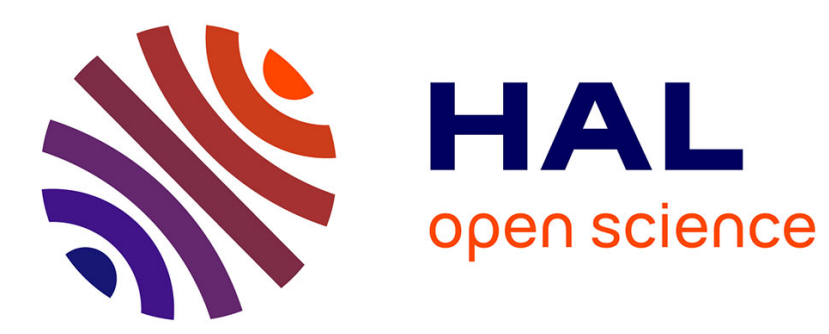

\title{
Natural Materials for Thermal Insulation: Mulch and Lava-Rock Characterizations
}

\author{
Aurélien Jean, Craig Adams, Mario Medina, Frédéric Miranville
}

\section{To cite this version:}

Aurélien Jean, Craig Adams, Mario Medina, Frédéric Miranville. Natural Materials for Thermal Insulation: Mulch and Lava-Rock Characterizations. Applied Mechanics and Materials, 2014, Machinery Electronics and Control Engineering IV, 705, pp.8 - 13. 10.4028/www.scientific.net/AMM.705.8 . hal-01110505

\section{HAL Id: hal-01110505 \\ https://hal.science/hal-01110505}

Submitted on $20 \mathrm{Jul} 2015$

HAL is a multi-disciplinary open access archive for the deposit and dissemination of scientific research documents, whether they are published or not. The documents may come from teaching and research institutions in France or abroad, or from public or private research centers.
L'archive ouverte pluridisciplinaire HAL, est destinée au dépôt et à la diffusion de documents scientifiques de niveau recherche, publiés ou non, émanant des établissements d'enseignement et de recherche français ou étrangers, des laboratoires publics ou privés. 


\title{
NATURAL MATERIALS FOR THERMAL INSULATION: MULCH AND LAVA-ROCK CHARACTERIZATIONS
}

\author{
Aurélien P. Jean 1,a , Craig Adams², Mario A. Medina², Frédéric Miranville ${ }^{1}$ \\ ${ }^{1}$ Physics and Mathematical Engineering Laboratory for Energy and Environment, University of Reunion, France \\ ${ }^{2}$ Civil, Environmental and Architectural Engineering Department, The University of Kansas, USA \\ aurelien.jean@univ-reunion.fr
}

Keywords: Natural materials; Thermal conductivity; Thermal characterization; Mulch; Lava-Rock; Construction.

\begin{abstract}
This paper reports on the thermal characterization, via the thermal conductivity, of natural materials, such as mulch and lava rock and their usefulness as building insulation. Experiments were carried out using a scale one monitored wall (i.e. heat flux and temperature sensors) exposed to a heating source on one side and to an air conditioned space on the other. The wall system was composed of an $8.85 \mathrm{~cm}$ thick cavity, where the mulch and lava rock were placed. The cavity was enclosed between two layers of pine wood $(40 \mathrm{~mm}$ thick each). After the experiments and statistical data manipulation, the estimated thermal conductivity of the materials were $0.48 \pm 0.001 \mathrm{~W} \cdot \mathrm{m}^{-1} \cdot \mathrm{K}^{-1}$ and $0.129 \pm 0.003 \mathrm{~W} \cdot \mathrm{m}^{-1} \cdot \mathrm{K}^{-1}$ for mulch and lava-rock, respectively. That is, mulch has a thermal conductivity comparable to that of bulk hemp while lava rock has a thermal conductivity comparable to that of hemp brick. These values indicate the usefulness of mulch, compared to the impracticality of using lava-rocks materials for building insulation.
\end{abstract}

\section{Introduction}

Knowledge of materials thermal characteristics is important to accurately predict their performance once these are integrated into more complex systems such as composite walls. This prediction is an indispensable condition for ecological building design ${ }^{1}$. Thermal properties are mostly obtained experimentally, following simplified approaches that may or may not resemble the conditions under which these materials will be used. Experiments to determine the thermal resistances, which were then converted to thermal conductivities, of natural materials, such as mulch and lava-rock, were carried out at the University of Kansas. This was part of an ongoing project by the student chapter of Engineers Without Borders (EWB) to design sanitation technologies, namely solar composting latrines for use in developing nations. The objective of this research was to thermally characterize some natural materials that would be available, inexpensive, and easily accessible to the people in locations where the latrines would be deployed. Those materials with the most favorable thermal characteristics (i.e., low thermal conductivity) would be selected for further study.

Mulching is an integral component of conservation farming and soil management. It is considered an essential building block for sustainable agriculture because of its agro-ecological potential. That is, it typically conserves the soil, enhances soil ecology and stabilizes crop yield [1].

In addition, with proper farming practices, mulch can be readily available and accessible to a significant portion of the population in developing nations. Volcanic lava rock can be found in almost every country around the world. In many developing nations, this type of rock is used as crushed rock in construction and highway engineering.

\footnotetext{
1 Environment meaning is used both as "nature" and "surrounding" definitions here.
} 


\section{Set up and methods}

To obtain thermal resistances, and then convert them to thermal conductivities, of both mulch and lava-rock a scale one monitored set up was used. The set up was made of a four-sided enclosure (walls) where a heat source that was placed at the center and equidistant from all internal sides of the enclosing walls (Figure 1). This approach was used to overcome a shortcoming usually found in the determination of thermal resistances when traditional methods, namely the hot box method [2] and the transient plane source technique [3] are used. The shortcomings relate to the fact that these traditional methods eliminate the presence of mass transfer in the form of air and moisture during the heat transfer process. In addition, these methods also eliminate heat exchanges between the wall and its surroundings. Therefore, when using these methods, a part of the energy exchanges may not be accounted for. Figure 2 depicts a side view of the set-up and presents the observed physical phenomena.

The controlled enclosure notion was chosen to closely reproduce the environmental conditions of the sanitations systems. Among the characteristics of the set up, the following were of upmost importance: first, the temperatures of the surfaces facing the heating source had the capacity to reach up to $45^{\circ} \mathrm{C}$. This was done to impose a high-enough heat flux across the wall sections and also because composting systems tend to achieve relatively high temperatures.
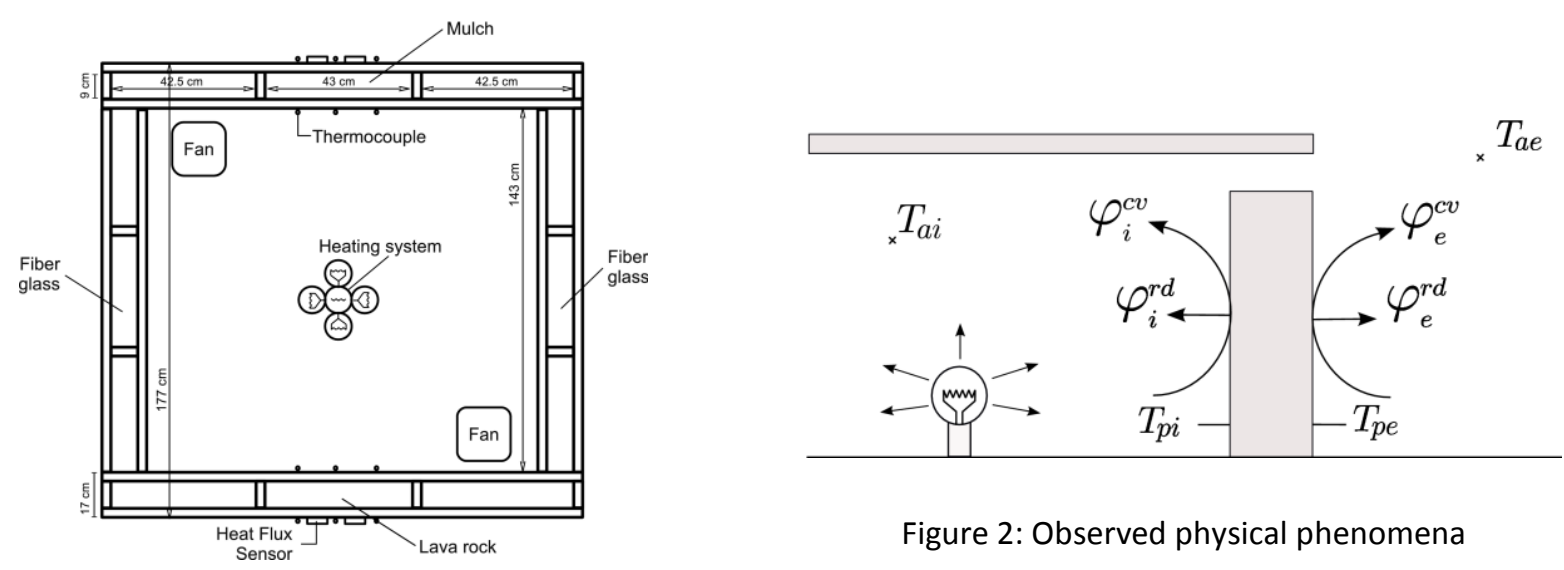

Figure 2: Observed physical phenomena

Figure 1: Experimental set-up schematic

A second set-up characteristic was that it closely resembled the walls of the composting compartments of the latrines. For this, the enclosing walls were made of wood ${ }^{2}$ with $4 \mathrm{~cm} \mathrm{x} 9 \mathrm{~cm}$ studs that separated each wall cavity every $43 \mathrm{~cm}$. The cavities were filled with samples of the materials that were to be characterized. This allowed for the accurate estimation of the thermal resistances of the walls. To estimate the thermal resistances of the walls, heat fluxes across the walls were measured and recorded first. The heating system that imposed the heat fluxes across the walls was composed of five $100 \mathrm{~W}$ light-bulbs that created a homogeneous radiative heat flux on each internal wall surface ${ }^{3}$. Two small fans were used to obtain a well-mixed air layer with no stratification. A partition was located $4 \mathrm{~cm}$ from the top of the walls to allow the hot air to exit the chamber to prevent over-heating (Fig. 2).

The room surrounding the set-up had a vent in the center of the ceiling that also allowed hot air to exit the laboratory naturally. Temperature and heat flux measurements were carried out according to methods presented by Childs [4] and Diller [5].

2 White Pine with a $\lambda_{\perp}$ estimated at $1.29 \mathrm{~W} \cdot \mathrm{m}^{-1} \cdot \mathrm{K}^{-1}$. ( $\lambda_{\perp}$ define the thermal conductivity perpendicularly to the wood fibers)

3 At least on the center of the walls where the sensors were located. This allowed the comparison between measurements and results. 
Experimentation. According to Cesaratto et al. [6], different parameters influence the in situ thermal resistance of a system. Samples of mulch and lava rock were placed inside the wall's cavity by layers of $15 \mathrm{~cm}$. Each of them had been weighted previously to ensure their density homogeneity. The mulch was in shaved form, where its length, width and thickness were between 2 to $4 \mathrm{~cm}, 0.3$ to $1 \mathrm{~cm}$, and 0.1 to $0.3 \mathrm{~cm}$, respectively. The lava-rock was crushed in blocks of 1 to 5 $\mathrm{cm}$ wide. These materials samples (inside the wall cavities) are shown in Figure 3.

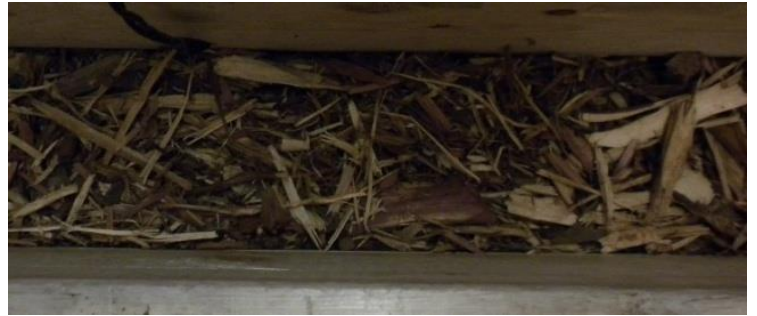

Figure 3.a: Mulch sample

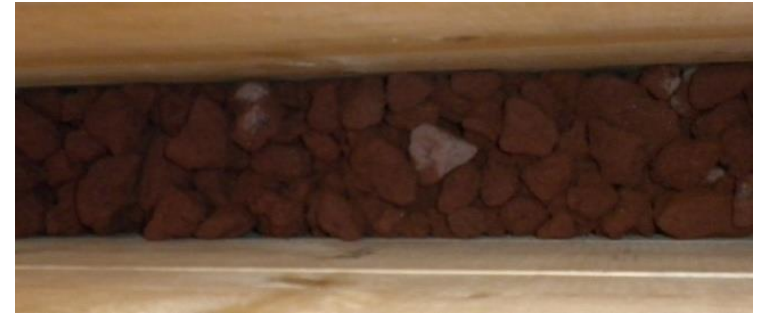

Figure 3.b: Lava rock sample

Once these samples were placed inside the wall cavities, the experiments were started. The heating system, fans, and the data logger were turned on. Because of the wall's thermal inertia (as a result of its mass), it took approximately 50 hours for it to reach steady state.

\section{Results}

Experimental heat flux densities are presented in Figure 4(a). It appeared that the heat transfer was higher in the wall insulated with the lava-rock. More precisely, the heat transfer was higher by a factor of approximately 1.7. The transient states observed in the graphs come from the variations of Tae. The relationship between the heat fluxes and the thermal gradient $(\Delta \mathrm{T}(\mathrm{pe}, \mathrm{ae}))$ was clearly visible in one graph of Figure 4(a). It appeared that the transient states represented a system continuously tending towards a steady state with its equilibrium value evolving accordingly to Tae. The fact that the heat fluxes were affected by $\Delta \mathrm{T}(\mathrm{pe}, \mathrm{ae})$ seemed reasonable because the heat flux sensors were located on the external side of the walls, which were exposed to Tae variations.

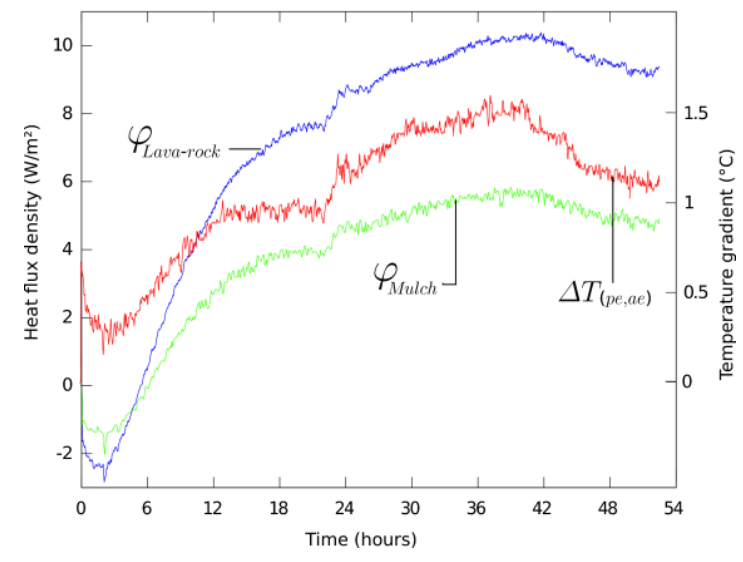

Figure 4.a: Heat flux densities and $\Delta \mathrm{T}(\mathrm{pe}, \mathrm{ae})$ on the instrumented walls.

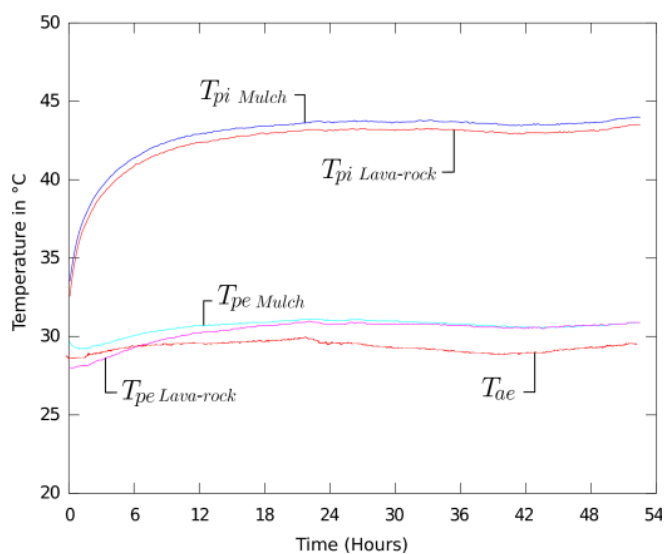

Figure 4.b: Temperatures on the instrumented walls.

Temperatures are presented in Figure 4(b). Unlike the heat fluxes, wall temperatures had a low variability. Unexpectedly, the internal temperatures (Tpi) difference between the test walls was greater than the difference between the external temperatures (Tpe). This comes from the unsteady values of the Tpi. That is, the boundary conditions at these locations are Neumann type. So the Tpi were free to vary. But, on the external side of the wall, the room temperature (Tae) was almost fixed (producing small variation). As a result, the external sides were exposed to convective and radiative 
fluxes, whose intensities varied according to the gradient between Tae and Tpe. These conditions led to homogenize the Tpe's to similar values.

Note: Tpi temperatures follow Tae simply because of the cavity between the walls and the top of the set-up (Fig. 2). From this consideration, Tae fluctuation led to Tai variation, inducing also the variation of the Tpi temperatures.

\section{Data manipulation}

To estimate the equivalent thermal resistance of the wall $\left(\mathrm{Rth}^{\mathrm{eq}}\right)$, it was necessary to find an adequate steady state condition during the course of the experiments. The selected steady-state-data had duration of seven hours (from $34 \mathrm{~h}$ to $41 \mathrm{~h}$ ). They also corresponded to the maximum heat flux values. From the steady-state-data, a linear regression was performed. This resulted in an equation with a slope close to zero (Eq.1 and 2). Moreover, the standard deviation of the noise around the equation was also small (respectively $0.17 \mathrm{~W} \cdot \mathrm{m}^{-2}$ and $0.56 \mathrm{~W} \cdot \mathrm{m}^{-2}$ for the Lava-rock and the Mulch). Therefore, the temporal evolution of the averaged heat fluxes was neglected, allowing the use of Fourier's equation to get the equivalent thermal resistance of the wall $\left(\mathrm{Rth}^{\mathrm{eq}}\right)$. Then using the additive property of thermal resistances in series, it was possible to extract the equivalent resistance of the samples (Rth*), namely the mulch and lava-rock.

Mulch linear regression:

$$
f(x)=0.0001 x+5.5238
$$

Lava-rock linear regression:

$$
f(x)=0.0001 x+9.9908
$$

From Rth*, the thermal conductivity of the samples $\left(\lambda^{*}\right)$ was obtained using equation 3 [7].

$$
\text { Rth*=e/Lambda*. }
$$

According to the experimental results (Table 1), mulch and lava rock have thermal conductivities of $0.48 \cdot 10^{-1} \pm 1 \cdot 10^{-3} \mathrm{~W} . \mathrm{m}^{-1} \cdot \mathrm{K}^{-1}$ and $1.29 \cdot 10^{-1} \pm 3 \cdot 10^{-3} \mathrm{~W} . \mathrm{m}^{-1} \cdot \mathrm{K}^{-1}$, respectively. By comparison, mulch has a thermal conductivity close to that of bulk hemp [8] and lava-rock has a thermal conductivity close to that of hemp brick (for a density of $25 \mathrm{~kg} \cdot \mathrm{m}^{-3}$ ) [9].

In addition, these results have been tested and validated by Jean et al [10] and the CodyRun software [11]. This last validation consisted in the simulation of walls using these mulch and lavarock thermal properties and comparing them with experimental data.

Table 1: Mulch and lava-rock samples thermal conductivities and resistances 4

\begin{tabular}{lcc} 
& Conductivity: $\lambda_{\mathrm{x}, \mathrm{y}}\left[\mathrm{W} . \mathrm{m}^{-1} \cdot \mathrm{K}^{-1}\right]$ & Resistance: $\mathrm{R}\left[\mathrm{m}^{2} . \mathrm{K} . \mathrm{W}^{-1}\right]$ \\
\hline Mulch & $0.48 \cdot 10^{-1} \pm 1 \cdot 10^{-3}$ & $1.93 \pm 2 \cdot 10^{-2}$ \\
Lava-rock & $1.29 \cdot 10^{-1} \pm 3 \cdot 10^{-3}$ & $0.710 \pm 7 \cdot 10^{-3}$ \\
\hline
\end{tabular}

\section{Discussion}

After the experiments and statistical data manipulations, the resistances of mulch and lava rock were estimated at $1.93 \pm 210^{-2} \mathrm{~m}^{2} . \mathrm{K} . \mathrm{W}^{-1}$ and $7.110^{-1} \pm 710^{-3} \mathrm{~m}^{2} . \mathrm{K} \cdot \mathrm{W}^{-1}$, respectively. Comparatively, a wall with an empty (except for air) cavity had a resistance of $1.0 \mathrm{~m}^{2} . \mathrm{K}^{\mathrm{W}} \mathrm{W}^{-1}$. These values clearly state the usefulness of the mulch and the impracticality of using lava-rock as insulation materials. So these materials could lead to maximize the energy saving. It could be used instead of a traditional insulation (polystyrene), or in addition of it. Furthermore, mulch and lavarock are often easily accessible, which could make these materials very useful in developing

$4 \lambda_{\mathrm{x}, \mathrm{y}}$ defines the thermal conductivity into the horizontal plane, so parallel to the heat flux. 
nations.

The benefits for the mulch as a better insulator than lava rock come from the low convection and low conduction through the material layer. Whereas, for the lava rock, the lost of insulation value seemed to come from a higher conductivity of the rock (vs. the conductivity of mulch) and probably as a result of more air convection between the rocks.

Considering the experiments, the estimated thermal conductivity values are only valid for the conditions under which the experiments were carried out (i.e., for the temperature and relative humidity ranges existent in and around the set up during the experiment.) Relative humidity ranged between $53 \%$ and $67 \%$ and air temperature ranged between $28^{\circ} \mathrm{C}$ and $34^{\circ} \mathrm{C}$. The extrapolation of the thermal conductivity for other ranges was not evident.

\section{Conclusions}

This paper presents the thermal characterization, via thermal conductivities, of mulch and lava rock. A scale one based experiment was carried out. According to the results, mulch and lava-rock had thermal conductivities of $0.48 \cdot 10^{-1} \pm 1 \cdot 10^{-3} \mathrm{~W} \cdot \mathrm{m}^{-1} \cdot \mathrm{K}^{-1}$ and $1.29 \cdot 10^{-1} \pm 3 \cdot 10^{-3} \mathrm{~W} \cdot \mathrm{m}^{-1} \cdot \mathrm{K}^{-1}$, respectively. By comparison, mulch has the thermal conductivity of bulk hemp and lava rock has a thermal conductivity close to that of hemp brick. For the composting compartment of a solar latrine, mulch seems to be a better insulator. Whereas, the lava-rock seems to be a poor insulator (about 1.7 times less than mulch). For the same thermal insulation as the mulch, the use of lava-rock would require a very thick and heavier layer of about $+70 \%$ and $+235 \%$, respectively. Consequently lavarock should not be used as building insulation.

\section{Acknowledgement}

The authors thank the Civil, Environmental and Architectural Engineering Department of the University of Kansas, the Haute Normandie region (France) and its "Region without border" financial program support, and the help of Mr. Jim Weaver and Mr. Matthew Maksimowicz. Without their support this would not have been possible.

\section{Nomenclature}

Latin Letters

\begin{tabular}{llr} 
Name & Denomination & Unit \\
\hline Req & Equivalent thermal resistance of the wall & $\mathrm{m}^{2} \cdot \mathrm{K}^{-\mathrm{W}^{-1}}$ \\
Rth & Thermal resistance of the sample & $\mathrm{m}^{2} . \mathrm{K}^{-\mathrm{W}^{-1}}$ \\
$\mathrm{e}$ & Material thickness & $\mathrm{M}$ \\
Tai & Internal air temperature & ${ }^{\circ} \mathrm{C}$ \\
Tae & External air temperature & ${ }^{\circ} \mathrm{C}$ \\
Tpi & Surface temperature on the outside of the internal partition & ${ }^{\circ} \mathrm{C}$ \\
Tpe & Surface temperature on the outside of the external partition & ${ }^{\circ} \mathrm{C}$ \\
\hline
\end{tabular}

Greek Letters

\begin{tabular}{llr} 
Name & Denomination & Unit \\
\hline$\varphi^{\mathrm{eq}} \mathrm{i}_{\mathrm{i}}$ & Equivalent thermal flux into the wall & $\mathrm{W}$ \\
$\varphi^{\mathrm{eq}}$ & Equivalent thermal flux out of the wall & $\mathrm{W}$
\end{tabular}


$\varphi_{\mathrm{cv}} \quad$ Convective flux on the external side of the wall $\quad \mathrm{W}$

$\varphi_{\text {rd }} \quad$ Radiative flux on the external side of the wall $\quad$ W

$\begin{array}{lll}\lambda_{*} & \text { Thermal conductivity of the sample } \quad \mathrm{W} \cdot \mathrm{m}^{-1} \cdot \mathrm{K}^{-1}\end{array}$

$\lambda_{x, y} \quad$ Thermal conductivity in the plane $\quad W \cdot m^{-1} \cdot K^{-1}$

$\lambda_{\perp} \quad$ Thermal conductivity perpendicularly to the wood fibers $\quad \mathrm{W} \cdot \mathrm{m}^{-1} \cdot \mathrm{K}^{-1}$

\section{References}

[1] Erenstein, O. (2003), 'Smallholder conservation farming in the tropics and sub-tropics: a guide to the development and dissemination of mulching with crop residues and cover crops.' Agriculture, Ecosystems and Environment 100, 17-37.

[2] Asdrubali, F. and Baldinelli, G. (2011), 'Thermal transmittance measurements with the hot box method: Calibration, experimental procedures, and uncertainty analyses of three different approaches', Energy and Buildings 43(7), 1618 - 1626.

[3] Bouguerra, A., Aït-Mokhtar, A., Amiri, O. and Diop, M. (2001), 'Measurement of thermal conductivity, thermal diffusivity and heat capacity of highly porous building materials using transient plane source technique', International Communications in Heat and Mass Transfer 28(8), $1065-1078$.

[4] Childs, P. (2001), Practical temperature measurement, Oxford GB: Butterworth-Heinemann. Desogus, G., Mura, S. and Ricciu, R. (2011), 'Comparing different approaches to in situ measurement of building components thermal resistance', Energy and Buildings 43(10), 26132620.

[5] Diller, T. (1999), Heat flux. In: The Measurement Instrumentation and Sensors Handbook, Boca Raton, Florida: CRC Press LLC.

[6] Cesaratto, P., De Carli, M. and Marinetti, S. (2011), 'Effect of different parameters on the in situ thermal conductance evaluation', Energy and Buildings 43(7), 1792-1801.

[7] Kreith, F., Boehm, R., George, D. Raithby, G.D., Hollands, K.G.T., Suryanarayana, N.V., Modest, M.F., Carey, V.P., Chen, J.C., Lior, N., Shah, R.K., Bell, K.J, Moffat, R.J., Mills, A.M., Bergles, A.E., Swanson, L.W., Antonetti, V.W., Irvine, T.F. Jr., and Capobianchi, M., (1999), Mechanical Engineering Handbook, Boca Raton: CRC Press LLC, chapter Heat and Mass Transfer, pp. 4-1 to 4-287.

[8] Kymäläinen, H.-R. and Sjöberg, A.-M. (2008), 'Flax and hemp fibres as raw materials for thermal insulations', Building and Environment 43(7), 1261 - 1269.

[9] Arnaud, L. (2000), Mechanical and thermal properties of hemp mortars and wools: experimental and theoretical approaches, in 'BIORESOURCE HEMP 2000 and other fibre crops', nova-Institut und Tritec, Wolfsburg 13-16.

[10]Jean, A. P., Boyer, H., Adams, C., Fakra, A. H., Medina, M. and Miranville, F. (2012), De la simulation du compartement thermique d'une paroi à l'observation d'état: l'assimilation de données dans codyrun en vue de la validation des propriétés thermiques d'un matériau, in 'Second Esim conference', Halifax, Nova Scotia.

[11]Boyer, H., Chabriat, J., Grondin-Perez, B., Tourrand, C. and Brau, J. (1996), 'Thermal building simulation and computer generation of nodal models', Building and Environment 31 (3), 207-214. 